\title{
ANALISIS PELAKSANAAN PELAYANAN OBSTETRI NEONATAL EMERGENCY KOMPREHENSIF (PONEK) DI RSUD Dr. PIRNGADI MEDAN TAHUN 2019
}

\author{
Hana Dhini Julia Pohan, Sudiro, Arifah Devi Fitriani \\ Program Studi S-2 IKM Fakultas Kesehatan Masyarakat, Institut Kesehatan Helvetia \\ Email : hanadhinijuliapohan@gmail.com
}

\begin{abstract}
Infant mortality has a close relationship with the quality of maternal care, so the process of childbirth and baby care must be in an integrated system at the national and regional levels. The study was conducted at Dr. Pirngadi Hospital Medan 2019. The research aims at describing the administration and management of PONEK, describing the adequacy of PONEK HR, and describing the fulfillment of PONEK facilities. This research approach is descriptive qualitative with data collection techniques through interviews. The informants of this study were the PONEK Implementation Team and the PONEK Management Team with a total of 8 people. The research instrument was the researcher himself and the collection of data through interviews and documentation. Processing and analysis of data used in the Content Analysis method. The results of the study were that the PONEK funding source comes from the Regional Public Service Agency. Incorrect PONEK Team Placement. Many PONEK Team members have not yet received PONEK training and certificates. 24-hour PONEK facilities. Blood supply of RSUD Dr. Pirngadi Medan is a Blood Transfusion Unit. The conclusion of the research is that management and administration are less than optimal. The PONEK executive officer does not get special PONEK incentives. The placement of Human Resources in implementing PONEK officers is not in accordance with their main tasks and functions, many PONEK Team members have not received PONEK certificate training but have provided emergency obstetric services. PONEK facilities serve 24 hours. The suggestion is that the budget for the procurement of facilities be proposed in the Regional Revenue and Expenditure Budget / Medan Government so that the Regional Public Service Board budget obtained by the hospital can be used optimally for the need to improve PONEK training and provide special PONEK incentives for PONEK implementing officers.
\end{abstract}

Keywords : PONEK, MNCHN, Ministry of Health RI

\begin{abstract}
Abstrak
Kematian bayi mempunyai hubungan erat dengan mutu penanganan ibu, maka proses persalinan dan perawatan bayi harus dalam sistem terpadu di tingkat nasional dan regional. Penelitian dilakukan di RSUD Dr. Pirngadi Medan Tahun 2019. Penelitian bertujuan mendeskripsikan administrasi dan pengelolaan PONEK, mendeskripsikan kecukupan SDM PONEK, dan mendeskripsikan pemenuhan fasilitas PONEK. Pendekatan penelitian ini deskriptif kualitatif dengan teknik pengumpulan data melalui wawancara. Informan penelitian ini Tim Pelaksana PONEK dan Tim Manajemen PONEK dengan jumlah seluruhnya 8 orang. Instrument penelitian adalah peneliti sendiri dan pengumpulan data melalui wawancara dan dokumentasi. Pengolahan dan analisis data menggunakan metode Content Analysis. Hasil penelitian adalah Sumber dana PONEK berasal dari Badan Layanan Umum Daerah. Penempatan Tim PONEK yang tidak sesuai. Banyak anggota Tim PONEK yang belum mendapatkan pelatihan dan sertifikat PONEK. Fasilitas PONEK 24 jam. Persediaan darah RSUD Dr. Pirngadi Medan bersifat Unit Transfusi Darah. Kesimpulan penelitian yaitu Pengelolaan dan administrasi kurang maksimal. Petugas pelaksana PONEK tidak mendapatkan insentif khusus PONEK. Penempatan Sumber Daya Manusia petugas pelaksana PONEK tidak sesuai tupoksinya, banyak anggota Tim PONEK yang belum mendapatkan pelatihan
\end{abstract}


sertifikat PONEK tetapi sudah memberikan pelayanan obstetri emergensi. Fasilitas PONEK melayani 24 jam. Saran yaitu anggaran pengadaan fasilitas diusulkan dalam Anggaran Pendapatan dan Belanja Daerah/Pemerintah Kota Medan, sehingga anggaran Badan Layanan Umum Daerah yang didapat rumah sakit bisa digunakan secara maksimal untuk kebutuhan meningkatkan pelatihan PONEK dan pemberian insentif khusus PONEK bagi petugas pelaksana PONEK.

Kata kunci : PONEK, MNCHN, Kemenkes RI

\section{PENDAHULUAN}

Penyebab kematian terbanyak neonatus usia 0-6 hari antara lain gangguan atau kelainan pernafasan, prematuritas, dan sepsis. Ketiga hal tersebut harus dapat dihindari. Kendala yang dihadapi masih berkisar antara keterlembatan pengambilan keputusan, merujuk dan mengobati. Sedangkan kematian ibu umumnya disebabkan perdarahan, eklampsia, infeksi, dan abortus. Mengingat kematian bayi mempunyai hubungan erat dengan mutu penanganan ibu, maka proses persalinan dan perawatan bayi harus dilakukan dalam sistem terpadu di tingkat nasional dan regional.

Berdasarkan penelitian World Health Organization (WHO), diseluruh dunia terdapat kematian ibu sebesar 500.000 jiwa pertahun dan kematian bayi, khususnya neonatus, sebesar 10.000.000 jiwa pertahun. Kematian maternal dan bayi tersebut terjadi terutama di negara berkembang sebesar 99\%. Penyebab langsung kematian ibu adalah dikarenakan perdarahan (42\%). Penyebab lain, yaitu eklampsi (25\%), infeksi (3\%), partus lama (3\%), abortus (5\%), dan lain-lain (22\%). Penyebab kematian Janin dan bayi terkait dengan kehamilan dan persalinan adalah BBLR (31\%), asfiksia $(19 \%)$, hiportermi $(6 \%)$, diare $(4 \%)$, infeksi (2\%), campak (1\%), dan lain-lain (36\%) (Dainty, 2017).

Berdasarkan United Nations Population Fund (UNFPA) menetapkan standar perawatan darurat untuk kebidanan dan bayi baru lahir adalah Perawatan dasar dan komprehensif, yaitu Perawatan obstetri dan bayi baru lahir dasar sangat penting untuk mengurangi kematian ibu dan bayi baru lahir. Perawatan ini, yang dapat diberikan dengan staf ahli di pusat-pusat kesehatan, besar atau kecil, termasuk kemampuan untuk: 1) Pemberian antibiotik, obat uterotonik (oksitosin) dan antikonvulsan (magnesium sulfat), 2) Pengangkatan plasenta secara manual, 3) Penghapusan produk yang ditahan setelah keguguran atau aborsi, 4)Persalinan pervaginam yang dibantu dengan ekstraktor vakum, 5) Perawatan resusitasi neonatal dasar. Perawatan obstetri dan bayi baru lahir yang komprehensif, biasanya diberikan di rumah sakit, mencakup semua fungsi dasar di atas, ditambah kemampuan untuk: 1) Melakukan operasi caesar, 2) Transfusi darah yang aman, 3) Penyediaan perawatan untuk bayi baru lahir yang sakit dan berat badan lahir rendah, termasuk resusitasi (UNFPA, 2014).

Intervensi terpenting untuk menjamin keselamatan ibu (safe motherhood) adalah memastikan bahwa setiap kelahiran dibantu oleh tenaga kesehatan yang kompeten dan memiliki keterampilan kebidanan, dalam kondisi darurat tersedia transportasi menuju fasilitas rujukan untuk perawatan kehamilan dan pesalinannya.Hal yang tak kalah pentingnya adalah memperkuat layanan kesehatan primer dan sistem rujukannya, serta meningkatkan kompetensi dan keterampilan tenaga kesehatan secara bersamaam untuk menjamin kualitas layanan kesehatan maternal dan neonatal (UNICEF, 2017).

Pelayanan obstetri dan neonatal regional merupakan upaya penyediaan pelayanan bagi ibu dan bayi baru lahir secara terpadu dalam bentuk Pelayanan Obstetri Neonatal Emergensi Komprehensif (PONEK) di Rumah Sakit dan Pelayanan Obstetri Neonatal Emergensi Dasar (PONED) tingkat Puskesmas.

Rumah sakit PONEK 24 jam merupakan bagian dari sistem rujukan pelayanan kedaruratan maternal dan neonatal, 
yang sangat berperan dalam menurunkan angka kematian ibu dan bayi baru lahir. Kunci keberhasilan PONEK adalah ketersediaan tenaga kesehatan yang sesuai kompetensi, prasarana, sarana dan manajemen yang handal. Untuk mencapai komptensi dalam bidang tertentu, tenaga kesehatan memerlukan pelatihan-pelatihan untuk meningkatkan pengetahuan, keterampilan dan perubahan perilaku dalam pelayanan kepada pasien (Kementerian, 2013).

Untuk melaksanakan tugasnya kepada masyarakat Kota Medan dan sekitarnya RSUD Dr. Pirngadi Medan berusaha memberikan pelayanan PONEK yang maksimal, dengan data kunjungan pasien obstetri dan neonatal dapat dilihat sebagai berikut : jumlah pasien obstetri dan neonatal di RSUD Dr. Pirngadi Kota Medan tahun 2016 sampai dengan tahun 2018 setiap tahunnya mengalami penurunan. Pada tahun 2016 pasien obstetri dan neonatal di RSUD Dr. Pirngadi Kota Medan sebanyak 448 pasien obstetri dan 354 pasien neonatal, tahun 2017 dengan jumlah pasien sebanyak 366 pasien obstetri atau turun $18,30 \%$ dan 363 pasien neonatal, dan tahun 2018 dengan jumlah pasien sebanyak 341 pasien obstetri atau turun sebanyak $6,83 \%$ dan 335 pasien neonatal.

Tabel 1.Data Kematian Neonatus di RSUD Dr. Pirngadi Medan

\begin{tabular}{|c|c|c|c|c|c|c|c|c|c|c|}
\hline \multicolumn{11}{|c|}{ Data Kematian Neonatus Di RSUD Dr. Pirngadi Medan } \\
\hline \multirow[b]{2}{*}{ No } & \multirow[b]{2}{*}{ Indikator } & \multicolumn{3}{|c|}{2016} & \multicolumn{3}{|c|}{2017} & \multicolumn{3}{|c|}{2018} \\
\hline & & $\begin{array}{c}\text { Jumlah } \\
\text { Kasus }\end{array}$ & $\begin{array}{l}\text { eningg } \\
\text { al }\end{array}$ & CFR & $\begin{array}{c}\text { Jumlah } \\
\text { Kasus }\end{array}$ & $\begin{array}{l}\text { Meningg } \\
\text { al }\end{array}$ & CFR & $\begin{array}{c}\text { Jumlah } \\
\text { Kasus }\end{array}$ & $\begin{array}{c}\text { Meningg } \\
\text { al }\end{array}$ & CFR \\
\hline 1 & Sepsis & 24 & 6 & $25 \%$ & 19 & 2 & $11 \%$ & - & - & - \\
\hline 2 & RDS & 82 & 34 & $41 \%$ & 125 & 61 & $49 \%$ & 115 & 43 & $37 \%$ \\
\hline 3 & $\mathrm{RD}$ & 62 & 17 & $27 \%$ & 42 & 7 & $17 \%$ & 42 & 4 & $10 \%$ \\
\hline 4 & $\begin{array}{l}\text { Neonatal } \\
\text { seizure }\end{array}$ & 28 & 5 & $18 \%$ & 17 & 1 & $6 \%$ & - & - & - \\
\hline 5 & $\begin{array}{l}\text { Kelainan } \\
\text { Kongenital }\end{array}$ & 42 & 20 & $48 \%$ & 43 & 20 & $47 \%$ & 44 & 19 & $43 \%$ \\
\hline 6 & BBLR & 102 & 47 & $46 \%$ & 98 & 17 & $17 \%$ & 96 & 10 & $10 \%$ \\
\hline 7 & Asfiksia & - & - & - & 10 & 4 & $40 \%$ & 11 & 1 & $9 \%$ \\
\hline 8 & GE & - & - & - & 6 & 1 & $17 \%$ & 10 & 1 & $10 \%$ \\
\hline 9 & $\begin{array}{l}\text { Bronchopneum } \\
\text { onia }\end{array}$ & - & - & - & - & - & - & 8 & 1 & $13 \%$ \\
\hline 10 & $\begin{array}{l}\text { Icterus } \\
\text { Neonatorium }\end{array}$ & - & - & - & - & - & - & 7 & 1 & $14 \%$ \\
\hline & Total & 340 & 129 & & 360 & 113 & & 333 & 80 & \\
\hline
\end{tabular}

Tabel 2. Data Kematian Obstetri di RSUD Dr. Pirngadi Medan Data Kematian Obstetri Di RSUD Dr. Pirngadi Medan

\begin{tabular}{llllllcccccc}
\hline \multirow{2}{*}{ No } & Indikator & \multicolumn{4}{c}{$\mathbf{2 0 1 6}$} & \multicolumn{4}{c}{2017} & \multicolumn{2}{c}{2018} \\
\cline { 3 - 13 } & & $\begin{array}{c}\text { Jumlah } \\
\text { Kasus }\end{array}$ & $\begin{array}{c}\text { Meningg } \\
\text { al }\end{array}$ & CFR & $\begin{array}{c}\text { Jumlah } \\
\text { Kasus }\end{array}$ & $\begin{array}{c}\text { Meningg } \\
\text { al }\end{array}$ & CFR & $\begin{array}{c}\text { Jumlah } \\
\text { Kasus }\end{array}$ & $\begin{array}{c}\text { Menin } \\
\text { ggal }\end{array}$ & CFR \\
\hline 1 & KJDK & 27 & 2 & $7 \%$ & - & - & - & - & - & - \\
\hline 2 & PE/E & 64 & 8 & 13 & 58 & 2 & $3 \%$ & 65 & 7 & $11 \%$ \\
& & & & $\%$ & & & & & & \\
\hline 4 & PPH & 58 & 2 & $3 \%$ & 56 & 2 & $4 \%$ & 58 & 1 & $2 \%$ \\
\hline 5 & Sepsis & - & - & - & 58 & 2 & $3 \%$ & 31 & 1 & $3 \%$ \\
\hline
\end{tabular}




\begin{tabular}{rrrrrrrrrrr}
\hline 6 & DLL & - & - & - & - & - & - & 21 & 1 & $5 \%$ \\
\hline & Total & $\mathbf{1 4 9}$ & $\mathbf{1 2}$ & & $\mathbf{1 7 2}$ & $\mathbf{6}$ & & $\mathbf{1 7 5}$ & $\mathbf{1 0}$ & \\
\hline
\end{tabular}

Survei awal yang dilakukan peneliti dengan menggunakan teknik wawancara dengan Sekretaris Tim Ponek pada tanggal 01 Maret 2019 di RSUD Dr. Pirngadi Medan didapatkan informasi bahwa RSUD Dr. Pirngadi menjalankan program PONEK sejak tahun 2012 dan mulai aktif tahun 2015. Secara umum implementasi PONEK sudah berjalan dengan baik, hal yang masih dianggap kurang yaitu $50 \%$ sumber daya manusia dibagian PONEK belum mengikuti pelatihan dan belum memiliki sertifikat PONEK di RSUD Dr. Pirngadi Medan. Hanya ada SK (Surat Keputusan) dari Walikota dan acuan kebijakan dalam pedoman penyelenggaraan pelayanan PONEK belum mengikuti pedoman penyelenggaraaan PONEK 24 jam di Rumah Sakit tahun 2012.

\section{METODE PENELITIAN}

Jenis Penelitian ini merupakan penelitian kualitatif dengan tema objek penelitian Pelayanan Obstetri Neonatal Emergency Komprehensif (PONEK). Oleh karena itu, penelitian dilakukan secara objektif, metode, dan konsep normatif. Penelitian kualitatif lebih ditujukan untuk mencapai pemahaman mendalam mengenai organisasi atau peristiwa khusus, ketimbang mendiskripsikan bagian permukaan dari sampel besar dari sebuah populasi. Berdasarkan analisis tersebut kemudian ditarik kesimpulan berupa pemahaman umum yang sifatnya abstrak tentang kenyataan kenyataan (Iman, 2015).

Penelitian ini dilakukan di RSUD DR. Pirngadi Medan. Informan dalam penelitian ini adalah tim pelaksana PONEK dan tim manajemen PONEK di RSUD DR. Pirngadi Medan sebagai berikut :

Tabel 3. Informan Penelitian

\begin{tabular}{lcc}
\hline \multicolumn{1}{c}{ Informan Utama } & Status & Jumlah \\
\hline Tim Pelaksana PONEK & & 1 \\
\hline Dokter IGD & Dokter IGD & 1 \\
\hline Bidan PONEK & Bidan IGD & 1 \\
\hline Perawat Pelaksana IGD & Perawat IGD & 1 \\
\hline Bidan IGD & Bidan IGD & Jumlah \\
\hline \multicolumn{1}{c}{ Informan Triangulasi } & Status & 1 \\
\hline Tim Manajemen PONEK & & 1 \\
\hline Kabid. Pelayanan Medis & Dokter & 1 \\
\hline Bid. Pelayanan Keuangan & Bag. Keuangan & 1 \\
\hline Ketua Tim Ponek & Dokter Sp. OG & \\
\hline Sekretaris II Tim Ponek & Bidan & \\
\hline
\end{tabular}

HASIL PENELITIAN

Administrasi dan Pengelolaan PONEK Di RSUD Dr. Pirngadi medan

Anggota PONEK Dokter Triase, Dokter Obgyn, Dokter Anak, Bidan, Perawat serta Tim PONEK tidak mendapatkan insentif khusus PONEK. Tim medis hanya mendapatkan gaji pokok dan hanya dibayar dari kalim BPJS. Yang 50\% sudah diambil dari jasa BPJS untuk fasilitas RS dan jasa pelayanan dibagi kembali ke dalam jasa bersama dan jasa medis sehingga penghasilan dari jasa medis dan jasa pelayanan jumlahnya tidak tetap yang diterima oleh petugas kesehatan setiap bulannya. Dengan demikian naik turunnya insentif yang diterima oleh para dokter, bidan dan perawat akan dirasakan sebagai pembagian yang tidak dapat diandalkan. Sehingga insentif tidak bisa dirasakan sebagai penghasilan tambahan yang memotivasi petugas medis dalam memberikan pelayanan kepada pasien. 
Hal ini dikarenakan sumber dana RSUD Dr. Pirngadi Medan berasal dari Badan Layanan Umum Daerah (BLUD). RSUD Dr. Pirngadi Medan disini mengelola sendiri semua dana yang masuk untuk dikelola serta menyalurkan di semua unit kerja rumah sakit. Maka dana yang diberikan BPJS dari klaim biaya pengguna pasien akan dikelompokkan ke dalam persentase jasa yaitu $50 \%$ jasa BPJS untuk fasilitas rumah sakit dan 50\% jasa pelayanan. Dalam jasa pelayanan akan dibagi kembali ke dalam jasa medis dan jasa bersama, dimana jasa medis untuk dokter dan jasa bersama untuk bidan, perawat dan tenaga medis.

Penyebabnya tidak terlaksananya program pelatihan PONEK yang telah direncanakan yaitu biaya pengganti dari pembayaran BPJS Kesehatan yang belum dibayarkan kepada pihak RSUD Dr. Pirngadi Medan, serta pelatihan medis lain yang menjadi skala prioritas, misalnya pelatihan Basic Trauma Cardiac Life Support (BTCLS), Advanced Cardiac Life Support (ACLS), Advanced Trauma Life Suppport (ATLS) dan lain-lain, dibandingkan dengan pelatihan PONEK di RSUD Dr. pirngadi Medan. Sumber dana PONEK berasal dari Badan Layanan Umum Daerah (BLUD), sehingga sebelum menyelenggarakan pelatihan dibuat Pagu Anggaran pelatihan. Bagian keuangan harus mampu mneghitung dan menyajikan anggaran yang digunakannya dalam kaitannya dengan layanan yang akan direalisasikan. Meskipun Pagu anggaran telah dibuat hal ini belum tentu terlaksana program pelatihan yang dibuat. Yang menjadi penyebab tidak terealisasinya program pelatihan antara lain kesanggupan anggaran yang tidak tercukupi dari target Pagu Anggran yang telah dibuat dan skala prioritas pelatihan lainnya baik pelatihan untuk tenaga medis maupun pelatihan non medis.

Pelaksanaan pelayanan PONEK tidak terlepas dari dukungan dana dari pemerintah. Semakin transparan dana yang disalurkan kepada rumah sakit PONEK maka semakin baik administrasi dan pengelolaan biaya PONEK yang telah dilaksanakan. Temuan diatas tidak sesuai dengan Maternal,
Neonatal and Child Health andNutrition (MNCHN) In Department of Health dimanasumber dana melalui anggaran dari Local Government Unit (LGU), Hibah Department Of Health (DOH), Pembayaran Umum (biaya pengguna), Biaya pengganti asuransi kesehatan akan digunakan untuk membiayai layanan Maternal, Neonatal and Child Health andNutrition (MNCHN) bahwa dana yang disalurkan dapat digunakan dalam layanan dan fasilitas, serta menambah kompensasi penyedia pelayanan (petugas kesehatan) (DOH, 2009).

\section{Sumber Daya Manusia PONEK Di RSUD Dr. Pirngadi medan}

Penempatan petugas pelaksana PONEK yang tidak sesuai akan mengganggu program PONEK. Padahal petugas sudah dilatih dan berkompeten serta mendapatkan sertifikat PONEK, tetapi tidak ditempatkan di ruang PONEK. Dalam PONEK bidan dan perawat tidak bisa menangani karena PONEK bukan melayani program melahirkan normal. Bidan hanya membantu dokter, dan dokter sebagai penanggungjawab pada pasien patologis di PONEK. Banyak bidan dan perawat di PONEK ini sudah menyalahi dan keliru. Karena aturannya Bidan menolong persalinan normal. Sehingga yang diperlukan itu dokter PONEK (Dokter yang berkompetensi PONEK) dan dokter spesialis yang menangani langsung secara cepat. Tetapi kalau hanya dokter PPDS apalagi dokter PPDS yang belum semester tinggi hal ini bisa dikatakan sama dengan dokter umum. padahal PONEK itu ditangani oleh dokter yang bersertifikat PONEK.

Sementara dokter PPDS yang menangani pasien obstetri neonatal emergensi belum memiliki sertifikat PONEK dan belum lulus spesialis. Maka program PONEK ini dirugikan di RSUD Dr. Pirngadi Medan. Karena dengan demikian tidak ada dokter spesialis yang memang khusus menangani PONEK (dikatakan yang sudah lulus). Maka tingkat kematian ibu dan kematian bayi tinggi di RSUD Dr. Pirngadi Medan masih tinggi. Ini sangat berbahaya dan menyalahi aturan kriteria RS Mampu 
PONEK. Karena pelaksanaan pelayanan PONEK tidak terlepas dari dukungan sumber daya manusia yang berkompeten. Sehingga ini sangat merugikan dan menyalahi aturan. Dengan PONEK dikerjakan oleh PPDS ini merugikan karena PPDS belum dokter spesialis kecuali dokter PPDS yang sudah lulus spesialis.

Padahal di luar negeri khusunya pada Maternal, Neonatal and Child Health andNutrition (MNCHN) In Department of Health dimana setiap anggota PONEK dilatih dan mengembangkan sumber daya manusianya sehingga memiliki kompetensi yang optimal. Dokter khusus PONEK dan dokter spesialis adalah petugas yang langsung menangani pasien obstetri neonatal emergensi dan masih diberikan pelatihan PONEK. Serta Latih dokter umum tentang pelatihanpenanganan kegawatdaruratan maternal dan neonatal. Dan kalau dokter tidak dapat memberikan pelayanan karena tidak dapat bekerja maka akan mengundang (kolaborasi) dengan dokter praktek swasta yang spesilisasi kebidanan-ginekologi, dokter anastesi, dokter anak yang bertindak sebagai konsultan atau dokter yang dikontrak dari luar rumah sakit.

Dengan memberikan insentif yang cukup kepada konsultan yang memberikan layanan kesehatan kepada pasien. Dokter yang memberikan pelayanan obstetri neonatal emergensi adalah memang benar dokter spesialis dan sudah tersertifikasi, serta bukan dokter PPDS apalagi dokter PPDS yang belum memiliki sertifikat PONEK dan tidak berkompeten.

Kebijakan ini menyerukan kepada para pemimpin kesehatan dan pemerintah daerah untuk memastikan persalinan yang dibantu oleh tenaga profesional yang terlatih dan berkompeten, dan tersetifikat. Berfokus terutama pada peningkatan keterampilan staf (dokter, perawat, bidan) yang telah menyelesaikan pelatihan PONEK termasuk yang sudah bekerja. Pimpinan bertangggung jawab mengenai pendidikan yang berkelanjutan, orientasi dan program pelatihan staf untuk menjaga kemampuan dan meningkatkan pelaksanaan PONEK.
Pendidikan yang berkelanjutan harus dikembangkan untuk tenaga dari unti/bagian tersebut, sehingga staf dapat meningkatkan pengetahuan, keterampilan, dan kemampuannya untuk melaksanakan tindakan dan prosedur baru. Sesuai dengan tuntutan masyarakat, serta IPTEK Kedokteran. Pelatihan berkala dalam bentuk On The Job Training (OTJ) perlu dikembangkan setiap bulan dalam memahami SOP/Protap.

Kementerian Kesehatan, Pemerintah Daerah, danRS PONEK sangat jarang mengadakan pertemuan koordinasi rutin dengan Tim Manajemen PONEK. Sehingga manajemen PONEKbelum terorganisir dengan baik. Kurangnya pemerintah memonitoring dan evaluasi efektifitas pengelolaan dana, yang mengakibatkan tidak terlaksana program pemerintah yaitu Tim PONEK yang belum mengikuti pelatihan dan belum memiliki sertifikat PONEK sesuai dengan penempatan dibidangnya. Program pemerintah membentuk pelatihan untuk meningkatkan pengetahuan dan mengembangkan keterampilan Tim PONEK. Hal ini tidak sesuai dengan Pedoman penyelenggaraan PONEK 24 jam di rumah sakit yang sudah dicanangkan oleh kementerian kesehatan RI.

Dalam setiap pembagian shift pagi, shift sore, dan shift malam di PONEK dibagi kedalam Dokter Obgyn sebanyak 1 orang dan ditambah dengan kewenangan PPDS, Dokter Triase Medical sebanyak 1 orang, Dokter Triase PONEK sebanyak 1 orang, Bidan PONEK sebanyak 2 atau 1 orang, Perawat PONEK sebanyak 2 atau 1 orang, PPDS Anastesi sebanyak 2 orang dan Supervisor sebanyak 1 orang. Setiap angggota PONEK yang bertugas kebanyakan dari angggota PONEK belum mengikuti pelatihan dan belum memiliki sertifikat PONEK. Meskipun anggota PONEK telah bertugas dalam memberikan pelayanan selama 7 hari dalam semingggu dan 24 jam dalam satu hari. Hal ini perlu merujuk pada pedoman syarat RS PONEK 24 jam yang diberlakukan oleh Kementerian Kesehatan RI 2012 dimana 
perlunya pelatihan PONEK yang diberikan pada anggota PONEK.

\section{Fasilitas PONEK Di RSUD Dr. Pirngadi Medan}

Fasilitas kesehatan harus memiliki sarana prasarana yang memadai, melayani kasus kegawatdaruratan kebidanan yang tersedia 24 jam dan 7 hari seminggu dikelola oleh tenaga yang terampil. Ketersediaan sarana dan prasarana sangat mendukung keberhasilan suatu program pelayanan PONEK serta pengimplementasiannya akan sangat mudah apabila didukung oleh fasilitas PONEK yang lengkap serta memadai.

Fasilitas PONEK di RSUD Dr. Pirngadi Medan yang mencakup kelengkapan perlengkapan PONEK, penyediaan alat dan bahan PONEK, pemeliharaan alat, penggunaan kamar operasi PONEK (24 jam), kamar bersalin PONEK (24 jam), pelayanan dan persediaan darah PONEK, pelayanan penunjang seperti laboratorium dan radiologi (24 jam) semua informan menjawab sama maka hal ini dapat dipastikan tingkat keakuratannya $100 \%$.

Pelaksanaan pelayanan PONEK tidak terlepas dari dukungan fasilitas PONEK yang layak digunakan. Temuan diatas sesuai dengan Maternal, Neonatal and Child Health andNutrition (MNCHN) In Department of Health dimana dukungan dari manajemen Department of Health (DOH) harus memastikan bahwa sistem dukungan yang berkelanjutan dan handal dengan tersedianya layanan yang efisien. Tujuan utama dari strategi Maternal, Neonatal and Child Health andNutrition (MNCHN) secara berkelanjutan adalah memberikan layanan pada fasilitas kesehatan PONED dan PONEK. Hal ini tercapai jika fasilitasfasilitas berkelanjutan secara finansial dan tidak semata-mata bergantung pada pengeluaran anggaran.

Hospital Blood Bank sebuah fasilitas pelayanan darah di ruamh sakit, sebagaimana mestinya dilisensikan oleh DOH-BHFS (Bureau Of Health Facilities Services) dan Center for Health Development (CHD). $\begin{array}{ccr}\text { Salah } & \text { satu upaya } & \text { program } \\ \text { Kementerian } & \text { Kesehatan } & \text { RI adalah }\end{array}$ mempercepat penurunan AKI dan AKB di rumah sakit yaitu melalui kesiapan rumah sakit PONEK dalam pemantapan pelaksanaan pelayanan 24 jam. Fasilitas RS PONEK dan pelayanan penunjang 24 jam yang terlaksana merupakan sebagai wujud akuntabilitas dan responsiveness dalam menangani ANC dan persalinan khususnya pelayanan obstetri neonatal emergensi dan komprehensif. Hal ini sesuai dengan Pedoman penyelenggaraan PONEK 24 jam di rumah sakit yang sudah dicanangkan oleh kementerian kesehatan RI.

\section{KESIMPULAN}

Berdasarkan uraian hasil penelitian dan pembahasan, Penelitian ini dapat disimpulkan sebagai berikut :

1. Pengelolaan administrasi, koordinasi antara pelayanan medis, bagian keuangan, dan Tim manajemen PONEK yang kurang maksimal. Sumber dana PONEK berasal dari Badan Layanan Umum Daerah (BLUD). Petugas layanan yang masuk dalam anggota Tim PONEK tidak mendapatkan insentif khusus PONEK sebagai penambahan kompensasi.

2. Penempatan Sumber Daya Manusia petugas pelaksana PONEK tidak sesuai dengan tupoksinya. Banyak anggota Tim PONEK yang belum mengikuti pelatihan PONEK dan belum memiliki sertifikat PONEK, serta PPDS yang belum memiliki sertifikat PONEK tetapi sudah memberikan layanan kepada pasien obstetri emergensi. namun dalam kenyataannya jumlah SDM tenaga kesehatan (dokter, bidan, perawat) di ruangan IGD sudah cukup. Pelaksanaan Program Pelatihan PONEK RSUD Dr. Pirngadi Medan terlaksana 1 kali semenjak diresmikannya RS PONEK di Pirngadi. Hal ini juga sebagai dasar untuk menghemat anggaran pembiayaan pegawai. Sedangkan Tim Audit Maternal di daerah Kota medan berasal dari RSUD Dr. Pirngadi Medan. 
3. Fasilitas pelaksanaan Pelayanan Obstetri Neonatal Emergensi Komprehensif (PONEK) di RSUD Dr. Pirngadi Medan sudah 24 jam dalam memberikan pelayanan. Sudah terpenuhinya fasilitas PONEK di RSUD Dr. Pirngadi Medan. Fasilitaspenting sebagai pendukung dalam memberikan penanganan yang cepat dan tepat. Persediaan darah di RSUD Dr. Pirngadi Medan yang bersifat UTD. Sehingga persediaan darah setiap hari tersedia. Keluarga pasien yang mau mendonorkan darahnya di rumah sakit sudah bisa terlaksanan. Untuk fasilitas peralatan sudah sesuai dengan standar panduan PONEK. Serta pelayanan yang diberikan sudah terlaksana 24 jam.

\section{SARAN}

1. Bagi Dinas Kesehatan Kota Medan untuk melakukan monitoring dan evaluasi terhadap pelaksanaan PONEK Di RSUD Dr. Pirngadi Medan. Dalam pengelolaan anggaran pelatihan PONEK lebih sehat dan akuntabel sehingga dana dapat dialokasikan sesuai dengan kebutuhan.

2. Bagi Direktur Rumah Sakit disarankan untuk melakukan data pengawasan terhadap Tim PONEK. Berkaitan dengan SDM yaitu kegiatan pelatihan PONEK dilakukan 1 tahun sebanyak 2x pelatihan agar pelaksanaan pelayanan PONEK dapat berjalan dengan baik demi tercapainya target menurunkan AKI dan AKB.

3. Anggaran untuk pengadaan fasilitas diusulkan dalam APBD/Pemerintah Kota Medan. Sehingga anggaran BLUD yang didapat rumah sakit bisa dipergunakan secara maksimal untuk kebutuhan meningkatkan pelatihan PONEK dan pemberian insentif khusus PONEK bagi petugas pelaksana PONEK.

4. Mengadakan pelatihan PONEKsatu kali dalam setahun untuk peningkatan keahlian tenaga medis dalam penanganan obstetri dan neonatal yang emergensi. Terutama untuk PPDS agar memiliki sertifikat PONEK.
5. Pembuatan anggaran pelatihan kepada dokter umum, spesialis dan petugas kesehatan Tim PONEK untuk mengatasi kasus emergensi baik secara umum maupun emergensi obstetri-neonatal guna mendapatkan sertifikat PONEK sesuai dengan pedoman PONEK.

6. Untuk meningkatkan mutu pelayanan khususnya pelayanan program PONEK, menjalin kerjasama dengan para dokter (Konsultan PONEK dari rumah sakit lain) yang bisa membantu untuk meningkatkan pelayanan agar selalu sejalan dengan ilmu terbaru.

\section{REFERENSI}

Dainty, M. (2017). Asuhan Kebidanan Komunitas. Yogyakarta: Penerbit Andi.

DOH. (2009). Maternal Neonatal And Child Health And Nutrition (MNCHN) Strategy Manual Of Operations In Department Of Health (DOH).

Iman, M. (2015). Panduan Penyusunan Karya

Tulis Ilmiah Bidang Kesehatan Menggunakan Metode Ilmiah. Bandung: Citapustaka Media Perintis.

Kementerian, K. (2013). Pedoman Penyelenggaraan PONEK 24 Jam di Rumah Sakit. Jakarta: Kementerian Kesehatan RI. Direktorat Jenderal Bina Upaya Kesehatan.

UNFPA. (2014). Www.unfpa.org.

UNICEF. (2017). Www.unicef.org. 